\section{Correspondence}

Inge Depoortere, Translational

Research Center for

Gastrointestinal Disorders, Gasthuisberg O\&N1, Box 701, Herestraat, 49, 3000 Leuven, Belgium. E-mail:

inge.depoortere@med.kuleuven.be

\section{Keywords}

motilin; GSK962040; human; gastrointestinal tract; contractility

\section{Received}

3 May 2012

Accepted

7 May 2012

Translational Research Center for Gastrointestinal Disorders, Catholic University of Leuven, Leuven, Belgium

GSK962040 is a small selective motilin receptor agonist currently under investigation in clinical trials for the treatment of conditions associated with delayed gastric emptying. As reported in this issue of the British Journal of Pharmacology, Broad et al., studied for the first time the region-dependent contractile effects of motilin and GSK962040 in human smooth muscle strips. Both compounds facilitated cholinergically mediated contractions of human gastric antral muscle strips at low concentrations and induced smooth muscle contractions at high concentrations. The effect was less pronounced in the fundus and almost absent in the colon. The long-lasting facilitation of cholinergic responses in the antrum by GSK962040 compared with the fading responses to motilin may be of importance from a clinical point of view. The approach used by Broad et al. with human tissue is a validated model to identify motilin receptor agonists with therapeutic value.

\title{
LINKED ARTICLE
}

This article is a commentary on Broad et al., pp. 763-774 of this issue. To view this paper visit http://dx.doi.org/10.1111/ j.1476-5381.2012.02009.x

\section{Abbreviations}

EGFP, enhanced green fluorescent protein; MMC, migrating motor complex; MTLR, motilin receptor

The finding that the macrolide antibiotic erythromycin A is a motilin agonist that stimulates gastric emptying in patients with diabetic gastroparesis has stimulated the development of motilin agonists with the aim of generating a new class of gastroprokinetic agents (Peeters et al., 1989; Janssens et al., 1990). The first motilides, macrolide compounds without antibacterial activity but with motilin agonist activity, were developed in the early 1990s. Several large clinical trials with one of the lead compounds, ABT-229, were conducted, but the further development of the compound was stopped because ABT-229 failed to relieve symptoms in patients with functional dyspepsia (Talley et al., 2000) and diabetic gastroparesis (Talley et al., 2001).

After these negative trials, the development of motilin agonists with the complex macrolide structure was abandoned. Recently, a second generation of synthetic small non-peptide motilin agonists has been developed first by Bristol-Myers Squibb, for example, BMS-591348 (Li et al., 2004) and later on by GlaxoSmithKline, for example,
GSK962040 (Westaway et al., 2009) and RaQualia Pharma, for example, RQ-00201894 (Takahashi et al., 2010).

In general, studies on the mechanism of action of motilin have been hampered by the absence of a functional motilin receptor in the gastrointestinal tract of rodents. Nevertheless, many studies have been performed with motilin in other species. Initial studies were mainly focused on the smooth muscle effects of motilin in muscle strips from human, rabbit, cat and chicken (see De Smet et al., 2009). Neural responses to motilin were demonstrated, for the first time, with electrical field stimulation of strips of the chicken proventriculus (Kitazawa et al., 1995), and later on with strips from the rabbit antrum (Van Assche et al., 1997; Dass et al., 2003). The existence of motilin receptors located on nerves or smooth muscle-enriched preparations from human or rabbit tissue was further confirmed by receptor-binding studies (Van Assche et al., 1998; Miller et al., 2000).

The region-dependent contractile efficacy of motilin and the motilin agonist, GSK962040, was for the first time studied 
in detail in vitro in human intestinal tissue by Broad et al. (2012) and is reported in the current issue of BJP. The authors confirmed previous findings by Van Assche et al. (1997) in the rabbit antrum that motilin enhanced cholinergic neurotransmission at low doses and interacted directly with antral smooth muscle receptors at high doses. Similarly, in healthy volunteers, a low dose of erythromycin A was shown to induce a premature antral activity front via activation of a cholinergic pathway and an atropine-resistant, nonpropagating, contraction of prolonged activity, probably involving a muscular contraction at higher concentrations (Coulie et al., 1998).

Thielemans et al. (2002) showed that the potency of peptidyl and non-peptidyl motilin agonists to induce $\mathrm{Ca}^{2+}$ responses in $\mathrm{CHO}$ cells expressing the cloned human motilin receptor (CHO-MTLR cells) correlated with the potency to induce smooth muscle responses in the rabbit intestine, indicating that the motilin pharmacophore is well conserved among species. Dass et al. (2003) confirmed that the rabbit motilin receptor is a close orthologue of the human receptor in terms of sequence identity. All these studies suggest that the rabbit isolated stomach preparation is the best animal model to screen for motilin agonists with prokinetic potential in humans.

Dyspeptic symptoms have a heterogeneous origin and besides delayed gastric emptying and hypersensitivity to gastric distension, impaired accommodation to a meal seems to be an important pathophysiological mechanism.

Fundic contractions may impair accommodation and may have contributed to the worsening of symptoms observed in the clinical trial with ABT-229. Indeed, Cuomo et al. (2006) showed that infusion of motilin increased fasting fundic tone, reduced gastric accommodation and increased meal-induced satiation. The effect was not blocked by atropine, suggesting that motilin induces proximal stomach contraction via a receptor primarily located on smooth muscle. The study of Broad et al. (2012) investigated for the first time the effect of motilin on fundic contractions in vitro and found that, at low concentrations, motilin and GSK962040 facilitated the contractions elicited by electrical field stimulation. Interestingly, the smooth muscle response to GSK962040 was only half of the response to motilin in the fundus. This suggests that GSK962040 is less likely than motilin to affect fundic tone in vivo and to impair accommodation. In the antrum, the GSK compound was even without effect on the smooth muscle.

Previous studies investigating the effect of motilin or erythromycin A on the contractility of human colonic smooth muscle strips and on $\mathrm{Ca}^{2+}$ signalling in colonic smooth muscle cells in culture showed that motilin exerted weak direct excitatory smooth muscle effects (Van Assche et al., 2001). These observations were confirmed by Broad et al., but in addition the authors showed that motilin did not facilitate neural responses in the colon and that GSK962040 was without effect in the colon. It is therefore unlikely that the GSK compound can be used for the treatment of constipation. However, in vivo studies are needed to confirm this.

An important finding of the current study by Broad et al. (2012) was that cholinergic facilitation by motilin in the antrum faded, whereas facilitation by GSK962040 was long lasting. Similar observations were made with motilin in the rabbit antrum (Dass et al., 2003). Fading of the response to motilin may be consistent with its physiological role in the induction of phase 3 activity of the migrating motor complex (MMC). It has been shown that during phase 1 of the MMC, the human and canine small intestine is refractory to the action of motilin. Such a phenomenon could be explained by a down-regulation of motilin receptors caused by the rise in plasma motilin levels which accompanies phase 3 .

The motilin receptor follows the desensitization paradigm operative for most GPCR: phosphorylation of the receptor, recruitment of $\beta$-arrestin- 2 which targets the receptor to clathrin-coated pits, internalization, dephosphorylation and ligand dissociation, sorting to the recycling endosomes and trafficking of the receptor back to the plasma membrane (Lamian et al., 2006; Mitselos et al., 2008).

The desensitization of the motilin receptor, together with the wrong dosage selection, has been considered as an important reason for the clinical failure of ABT-229. In CHO-MTLR cells with enhanced green fluorescent protein (EGFP), ABT229 was a much more potent inducer of desensitization than motilin, EM-A and other motilides, because the compound induced a higher degree of internalization and delayed the recycling of the internalized receptors to the plasma membrane (Thielemans et al., 2005; Mitselos et al., 2008). An important feature of the GSK compound studied by Broad et al. (2012) was its long-lasting neural activity compared with motilin. It was suggested by the authors that GSK962040 may bind to a different site on the receptor from that used by motilin and, in this way, influence other downstream mechanisms. However, it is much more likely that GSK962040 may be less prone to induce desensitization of the motilin receptor. This is in line with previous observations showing that not all motilin agonists have the same desensitizing properties and that some compounds, for example, ABT-229, have a stronger desensitizing potency than would be expected on the basis of their activity (Thielemans et al., 2005). It would be interesting to compare the desensitizing but also the resensitizing properties of GSK962040 with those of motilin and ABT-229 in the in vitro CHO-MTLR-EGFP trafficking model of Mitselos et al. (2008). This would definitively validate the usefulness of the current in vitro model used by Broad et al. (2012) to screen for motilin agonists with clinical benefit in which the facilitating effect of the motilin agonist on gastric neuronal activity represents a model to test the activity of the compound, while the fading of the response would represent a measure for the desensitizing properties of the agonist.

In summary, GSK962040 seems to meet the criteria of an ideal motilin agonist. At low doses, the compound maximally activates gastric neuronal motilin receptors with no smooth muscle effects in the fundus which may impair accommodation. In addition, the long-lasting facilitation of the neural response by GSK962040 suggests that the compound does not induce receptor desensitization. Oral administration of GSK962040 as single or repeated doses accelerated gastric emptying in a maintained manner in healthy volunteers (Dukes et al., 2009; 2010). Preliminary results from phase 2 studies investigating the effect of single oral doses of GSK962040 for the treatment of gastroparesis in type 1 diabetes indicate that the compound is well tolerated and increases gastric emptying (Hellstrom et al., 2011). A similar study is going on in critically ill patients with enteral feed 
intolerance. The safety, efficacy and dose response of 28 days of once-daily oral dosing of GSK962040 will soon be tested in (type 1 or type 2) diabetic patients with gastroparesis.

These studies with GSK962040 could force a breakthrough for the further development of motilin receptor agonists with gastroprokinetic potential. In the future, the most important competitor of GSK962040 may be the oral ghrelin agonist, TZP-102, which has been tested in phase 2 studies in patients with diabetic gastroparesis with positive effects on both symptoms and gastric emptying rate (McCallum et al., 2011). After many years of pioneering work, the future will show which one of the two cognate peptides will receive the label of a new gastroprokinetic drug.

\section{Conflict of interest}

None.

\section{References}

Broad J, Mukherjee S, Samadi M, Martin JE, Dukes GE, Sanger GJ (2012). Regional- and agonist-dependent facilitation of human neurogastrointestinal functions by motilin receptor agonists. Br J Pharmacol 167: 763-774.

Coulie B, Tack J, Peeters T, Janssens J (1998). Involvement of two different pathways in the motor effects of erythromycin on the gastric antrum in humans. Gut 43: 395-400.

Cuomo R, Vandaele P, Coulie B, Peeters T, Depoortere I, Janssens J et al. (2006). Influence of motilin on gastric fundus tone and on meal-induced satiety in man: role of cholinergic pathways. Am J Gastroenterol 101: 804-811.

Dass NB, Hill J, Muir A, Testa T, Wise A, Sanger GJ (2003). The rabbit motilin receptor: molecular characterisation and pharmacology. Br J Pharmacol 140: 948-954.

De Smet B, Mitselos A, Depoortere I (2009). Motilin and ghrelin as prokinetic drug targets. Pharmacol Ther 123: 207-223.

Dukes G, Barton M, Dewit O, Hicks K, Vasist L, Van Hecken A et al. (2009). Pharmacokinetics, safety/tolerability, and effect on gastric emptying of the oral motilin receptor agonist, GSK962040, in healthy male and female volunteers. Neurogastroenterol Motil 21: 84 .

Dukes GE, Barton M, Dewit O, Stephens K, Vasist L, Young M et al. (2010). Safety/tolerability, pharmacokinetics (PK), and effect on gasric emptying (GE) with 14-days repeat oral dosing of the motilin receptor agonist, GSK962040, in healthy male and female volunteers. Neurogastroenterol Motil 22: 14.

Hellstrom PM, Tack JF, Stephens KE, Barton ME, Vasist LS, Richards DB et al. (2011). A double-blind, randomized placebo-conrolled phase II study of the pharmacodynamics, safety/tolerability, and pharmakokinetics of single doses of the motilin agonist GSK962040, in patients with type I diabetes mellitus TIDM) and gasroparesis. Gastroenterology 140: S813.

Janssens J, Peeters TL, Vantrappen G, Tack J, Urbain JL, De Roo M et al. (1990). Improvement of gastric emptying in diabetic gastroparesis by erythromycin. Preliminary studies. N Engl J Med 322: 1028-1031.
Kitazawa T, Taneike T, Ohga A (1995). Excitatory action of [Leu13]motilin on the gastrointestinal smooth muscle isolated from the chicken. Peptides 16: 1243-1252.

Lamian V, Rich A, Ma Z, Li J, Seethala R, Gordon D et al. (2006). Characterization of agonist-induced motilin receptor trafficking and its implications for tachyphylaxis. Mol Pharmacol 69: 109-118.

Li JJ, Chao HG, Wang H, Tino JA, Lawrence RM, Ewing WR et al. (2004). Discovery of a potent and novel motilin agonist. J Med Chem 47: 1704-1708.

McCallum R, Wo JM, Venuti RP, Esfandyari T, Jarnal MM, Dimcesyski G et al. (2011). TZP-102, ghreiln agonist phase 2 data: the improvement in symptoms of gastroparesis (nausea, early satiety, bloating and abdominal pain) significantly correlated with patient rating of overall treatment effect. Gastroenterology 140 (Suppl. 1): S807.

Miller P, Roy AS, Pierre S, Dagenais M, Lapointe R, Poitras P (2000). Motilin receptors in the human antrum. Am J Physiol Gastrointest Liver Physiol 278: G18-G23.

Mitselos A, Vanden Berghe P, Peeters TL, Depoortere I (2008). Differences in motilin receptor desensitization after stimulation with motilin or motilides are due to alternative receptor trafficking. Biochem Pharmacol 75: 1115-1128.

Peeters T, Matthijs G, Depoortere I, Cachet T, Hoogmartens J, Vantrappen G (1989). Erythromycin is a motilin receptor agonist. Am J Physiol 257: G470-G474.

Takahashi N, Koba N, Yamamoto T, Sudo M (2010). Characterisation of a novel, potent and selective small molecule motilin receptor agonist, RQ-00201894. Gastroenterology 138 (Suppl. 1): S713.

Talley NJ, Verlinden M, Snape W, Beker JA, Ducrotte P, Dettmer A et al. (2000). Failure of a motilin receptor agonist (ABT-229) to relieve the symptoms of functional dyspepsia in patients with and without delayed gastric emptying: a randomized double-blind placebo-controlled trial. Aliment Pharmacol Ther 14: 1653-1661.

Talley NJ, Verlinden M, Geenen DJ, Hogan RB, Riff D, McCallum RW et al. (2001). Effects of a motilin receptor agonist (ABT-229) on upper gastrointestinal symptoms in type 1 diabetes mellitus: a randomised, double blind, placebo controlled trial. Gut 49: 395-401.

Thielemans L, Depoortere I, Vanden Broeck J, Peeters TL (2002). The motilin pharmacophore in $\mathrm{CHO}$ cells expressing the human motilin receptor. Biochem Biophys Res Commun 293: 1223-1227.

Thielemans L, Depoortere I, Perret J, Robberecht P, Liu Y, Thijs T et al. (2005). Desensitization of the human motilin receptor by motilides. J Pharmacol Exp Ther 313: 1397-1405.

Van Assche G, Depoortere I, Thijs T, Janssens JJ, Peeters TL (1997). Concentration-dependent stimulation of cholinergic motor nerves or smooth muscle by [Nle13]motilin in the isolated rabbit gastric antrum. Eur J Pharmacol 337: 267-274.

Van Assche G, Depoortere I, Peeters TL (1998). Localization of motilin binding sites in subcellular fractions from rabbit antral and colonic smooth muscle tissue. Regul Pept 77: 89-94.

Van Assche G, Depoortere I, Thijs T, Missiaen L, Penninckx F, Takanashi H et al. (2001). Contractile effects and intracellular Ca2+ signalling induced by motilin and erythromycin in the circular smooth muscle of human colon. Neurogastroenterol Motil 13: 27-35.

Westaway SM, Brown SL, Fell SC, Johnson CN, MacPherson DT, Mitchell DJ et al. (2009). Discovery of N-(3-fluorophenyl)-1-[(4([(3S)-3-methyl-1-piperazinyl]methyl)phenyl)acetyl]-4-piperidinamine (GSK962040), the first small molecule motilin receptor agonist clinical candidate. J Med Chem 52: 1180-1189. 